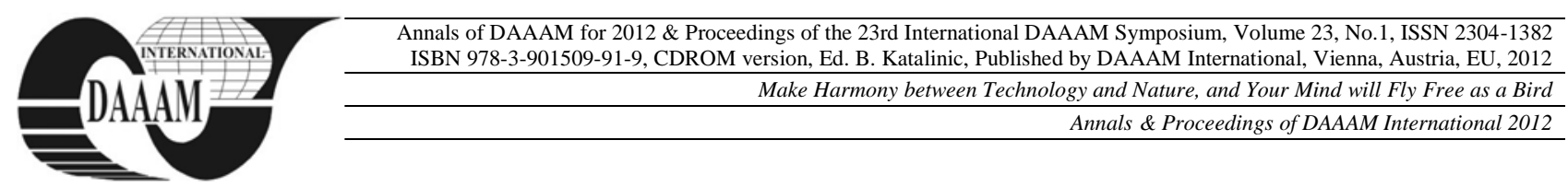

\title{
FUTURE VIRTUAL PROJECT MANAGEMENT DEVELOPMENT TRENDS
}

\author{
BANDIC GLAVAS, M[arijana] \& MAJSTOROVIC, V[lado]
}

\begin{abstract}
Future project management development trends, as well as project management computer support lead to development of virtual organizations, company nets worldwide (the Internet, extranet, intranet), new software and improving of existing ones, and all that with the aim to make work easier, development faster and to get competitive advantages on the market. Also, some topics, such as efforts to gain quality as a standard, improving of products as well as achieving excellence, innovations and adequate usage of new technologies are extremely pointed out. Project management is almost inconceivable without computer support. This paper deals with development trends of virtual project management with an emphasis on computer support for project management. Keywords: project management, virtual organization, computer support, internet
\end{abstract}

\section{INTRODUCTION}

We are witnessing dramatic changes that occur in organizations, and what is an advantage today, tomorrow it can become a disadvantage. The future is almost impossible to predict. The old way of doing business no longer meets needs of the market; companies on more developed markets are increasingly focused on project management with computer support. Small businesses become more competitive through the creation of business networks and virtual organizations, and through the Internet they can make close international cooperation and good relations with clients.

The turning-point in the development of project management happened in the middle of the century, when the development of this area became faster. Today, when the life cycle of even the most complex products gets shorter and shorter, it becomes impossible to survive on the market without some form of project management. Also, we must not forget the role of informatics technology, which made project management much sophisticated by introducing innovations such as software for planning and running projects support.

Today's developments in telecommunications and information technologies create new opportunities, and globalization provides geographically separated project team members throughout the world to work together, which leads to creation of so-called virtual teams that don't have to be located in one place, such as the case with traditional project teams. Trends for the future development of project management and computer support in this area go towards the development of virtual organizations, networks of companies around the world (Internet, extranet, intranet), new software and improvement of the existing ones in order to make the work easier, to accelerate the development as well as to achieve the competitive advantage on the market.

\section{NEW WAYS OF FORMING ORGANIZATIONS}

The rapid development of new information and telecommunication technologies opens a new world to modern organizations - the world of virtual organizations.

Reasons that are driving many organizations to implement virtual organization are [4]:

a. A need for process innovation;

b. Sharing of core competencies;

c. Globalization;

d. Mobile workers;

e. Cost reduction;

f. Changes in employee's values and attitudes toward work;

g. Costs and problems of traveling.

Modern organizations, taking into account the abovementioned reasons, do not have to be limited to one city or town when looking for employees. The best qualified employees can be found anywhere in the world. There is no regional limitation. Also, working hours are not limited to certain eight hours in a day, now they can use whole 24 hours in which everybody organizes his time that suits him best, and in that way organization becomes more flexible. Flexible organizations are more competitive on the market. They don't waste time on travel to work, which raises productivity. Costs are reduced and links are created among organizations. The market is developing in different parts of the world.

Virtualization is mostly spread in software industry, where through virtual media IT professionals working on IT projects meet each other and this allows them to work on joint projects, regardless of their mutual distance. In the real time information can be transmitted as audio / video materials through the Internet as a communication medium. Just because of that trend, organizations have to make project web sites, which are available to appropriate organizations and project team members from different geographic distances. That is the way to present and transfer important information to project team members, and virtual organization is actually created, which allows easier coordination and execution of projects on large regional distances.

Teams, in which there is no physical contact between individual members, are the teams of the future. Jobs are no longer performed in one office, but they are 
performed in offices in different, geographically remote places, with the support of new information technologies that allow easier virtual work (videoconferencing, electronic meetings, e-mail, Internet, etc.).

A lot of experts agree that a team is a basic unit of effectiveness in each organization, and today's virtual teams provide new views and better efficiency, higher quality and faster work as well as less expenses in order to help the organization to survive on increasingly demanding market.

However, virtual work has its disadvantages, and one of them is necessary IT knowledge that depends on many factors. The other disadvantage is limited amount of data during the transfer of textual information among project team members. Despite of all disadvantages, the work of virtual project teams is increasingly present, and state borders, geographic and time differences are no longer a problem for the communication of members of virtual project teams.

\section{INTERNET - INTRANET - EXTRANET}

In the recent twenty years in the field of project management three different types of linked computer nets have been used [9]:
a. Internet (since late 1980s);
b. Intranet (since 1996);
c. Extranet (since 1997).

The Internet is a global system of interconnected computer networks. It is not controlled by a central entity and therefore it relies on network devices and accepted conventions and protocols to relay the data traffic until it gets to its destinations. Today, the Internet offers almost everything. A number of libraries, newspapers, magazines, archives, international non-governmental organizations, ministries, embassies, faculties, institutes etc. It sounds a bit incredible, but almost the entire planetary knowledge is gathered in a single computer net - the Internet.

On the other hand, an intranet is a private network that is setup and controlled by an organization to encourage interaction among its members, to improve efficiency and to share information, among other things. The intranet is a restricted-access network that works similarly to the Internet, but it is isolated from it. The difference between the intranet and the Internet is defined in terms of accessibility, size and control.

The extranet is the extended intranet - a private business net, made by connecting the Intranet of some co-operational and partner organizations. It has been made because it was necessary to improve electronic business operations, and it provides revolutionary changes in structure and in operations of different organizations. Extranet is not available to everyone, and its usage is not limited within one organization only.

Both intranet and extranet are owned, operated and controlled by one organization. However, the difference between intranet and extranet is defined in terms of who has access to private network and the geographical reach of that network. The intranet allows only members of the organization to access the network, while the extranet allows persons from outside the organization (i.e. business partners and customers) to access the network.

The extranet is based on existing Internet infrastructure, and it replaces conventional ways of communication among organizations and makes direct connection with business partners. It provides faster and more efficient business operations and reduces expenses.

The following figure shows the relation of Internet, intranet and extranet from external net to the internal one:

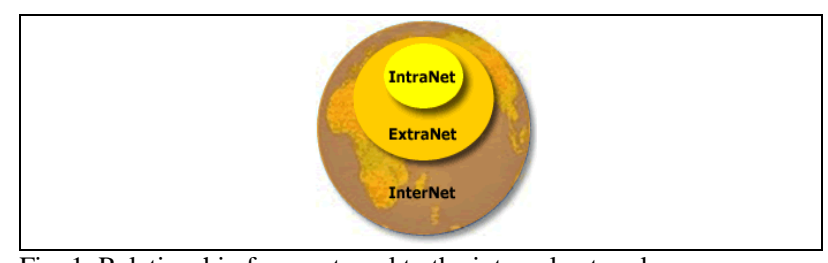

Fig. 1. Relationship from external to the internal network

The Internet, Intranet and Extranet can be used in different ways, but always with the aim to achieve competitive advantages in corporative environment, but the most important business innovation today is seen in contribution to communication, cooperation and relieving information.

\section{PROJECT MANAGEMENT AND COMPUTER SUPPORT}

Application of software systems for project management began in the mid 1970s. The former complex computer systems required the users' extensive knowledge; they were not user-oriented and were slow. User-oriented software's were developed simultaneously with the development of personal computers and they were appropriate to all types of projects and easily accessible due to low-cost software and hardware.

Today different types of software that allow process plans, create charts, a timetable and allocate resources are used for the purposes of project management and therefore more time is left for conversion and processing of multiple versions of plans, required for making more quality decisions.

From the very beginning, managers must carefully evaluate and select software that will meet their criteria, so that the software package could satisfy all project participants.

When manager plans a project schedule, it can be hard to find the perfect software for his project. There are certain features such as the ability to display Gantt and PERT charts that are a must. Then there are pricing concerns - some software assumes a much larger budget than the project might have. He might also need to consider usability - will his team members have a steep learning curve with a particular piece of software?

Currently, among the most commonly used software for project management are [1]:

1. Microsoft Project - many project managers like Microsoft Project because it's relatively easy to learn. It is pricier, making it less ideal for managers who need project scheduling software that fits in a tight budget. Microsoft Project is highly integrated, 
allowing tracking a number of variables and produce Gantt charts as well as network diagrams.

2. ZOHO Projects - there are several factors in $\mathrm{ZOHO}$ Projects' favor. It's a web-based application, meaning that there is not need for installation of project management software on each computer that is used. It is easy to access to the schedule from anywhere and, if it is working on one project, ZOHO Projects are free. ZOHO Projects can generate Gantt charts, but don't offer PERT charts.

3. FastTrack Schedule 9 - this schedule software, available for both Mac and Windows, has an extremely effective set of resource management tools built in. A license for FastTrack is significantly lower compared to ones necessary for Microsoft Project. For newer project managers, FastTrack offers an easy introduction to the software and a gentle learning curve. It's also robust enough for any experienced project manager that wants to put it through its paces.

4. Primavera P6 - the Primavera name is well-known in project management solutions. This software package is flexible and has the ability to handle everything from time sheets to resource management. However, it does have more extensive hardware requirements than some other project management applications. It is intended for use by larger organizations, and may not be ideal for managers working with smaller projects.

5. @ task - this web-based project management option focuses on an easy-to-use interface. Just a brief look at @task's Gantt charts shows some impressive utilities. It is easy to drag and drop information to avoid unnecessary typing, easily schedule individuals for specific tasks, and view real-time reports showing project's status. @task offers a variety of pricing plans depending on a number of users and a number of projects which must be managed.

Each of these project schedule software options has different strengths, and they offer the best options for a variety of management needs. These 5 types of software can be considered as top 5 scheduling software programs and the project manager must choose the program which, with its features, interface, cost and other criteria suits him the most.

\section{EXAMPLE OF A GOOD PRACTICE}

In this modern time, effectively planned and creative use of virtual space gives wide opportunities to achieve certain goals. Virtual space on the Internet became very attractive space which can be used for different types of marketing because the time that people spend on it is increasing. In this context, it is not an exception that political subjects use it for political marketing, especially for communication with certain target groups of citizens.

On the assumption that young and educated population of people mostly uses this space, some political subjects are trying to fit communication through popular social networks to the project of the political campaign. In Bosnia and Herzegovina Facebook was recognized as the most used social network with over 1.2 million registered profiles, which means that approximately every third resident is a potential "victim" of political marketing. [17]

Local branch of one political party in Bosnia and Herzegovina two years ago made a profile and corresponding Facebook page. Through different types of everyday revelations they succeed attract over 3.500 people ("likes on page"). Besides the Facebook page, second medium for transmitting and distributing content are real people who use their virtual profiles for different types of interaction with content on the Facebook page. These types of interactions can be comments, sharing or likes, which are visible to friends of people who are not directly in any way connected with this Facebook page. In this way, with a serious, committed, planned and systematic work that is well-timed and designed, 3.500 people has the capacity to deliver a message to more than 800.000 (viral capacity) "friends of friends" and even exported it across the city limits, regions, which in this case happened.

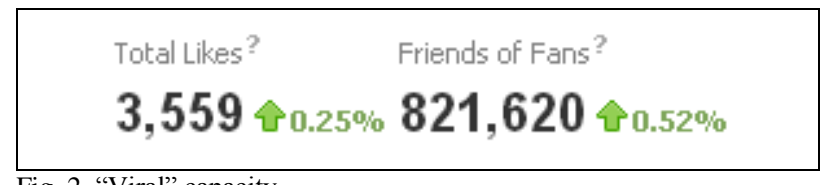

Fig. 2. "Viral" capacity

This political party decided that, in addition to the classic way of the election campaign in duration of one month, experimentally try out virtual campaign. They set up banners on local portals exclusively from the certain area and linked it with the regional Facebook page instead to the political party's website. The target group was young, educated people and the population of potential voters.

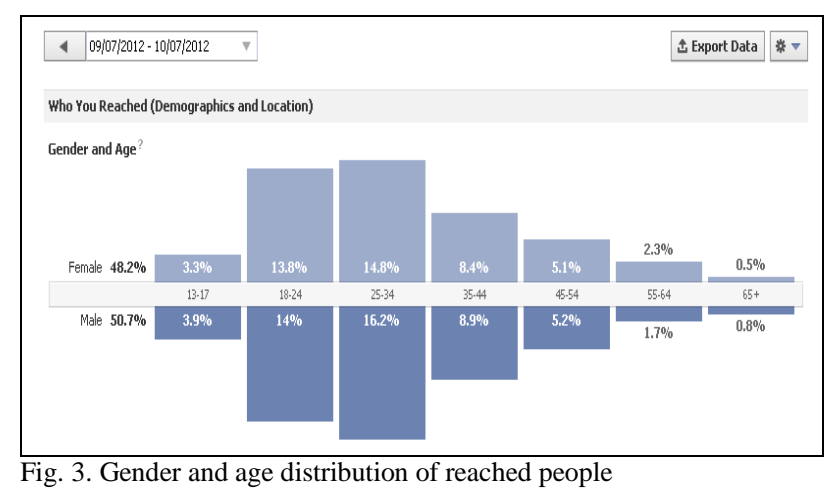

Placing this type of banner, interested citizens could by clicking on it directly go to this Facebook page. In this way political subject provided additional information to the potential voters through publications, videos and photos and made campaign cheaper.

During one month through these two portals and banners over 400 users come and view the content on the Facebook page. That means that 400 users received additional information and their attention is brought to the program of this political subject. Popularization of this page is reflected in the number of "likes" by users who have chosen that they will continue to monitor the publication and content on that page. 


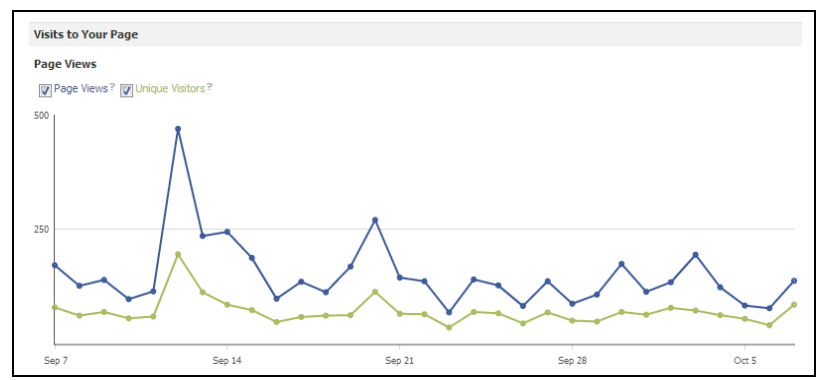

Fig. 4. Visits to the page

\begin{tabular}{|c|c|}
\hline \multicolumn{2}{|c|}{$\begin{array}{c}\text { The number of times people arrived from a URL that is not part of } \\
\text { facebook.com }\end{array}$} \\
\hline$U R L$ & No. \\
\hline grude-online.info & 336 \\
\hline google.ba & 330 \\
\hline boboska.com & 115 \\
\hline google.com & 16 \\
\hline google.hr & 10 \\
\hline search.mywebsearch.com & 6 \\
\hline images.google.com & 5 \\
\hline
\end{tabular}

Tab. 1. External referrers

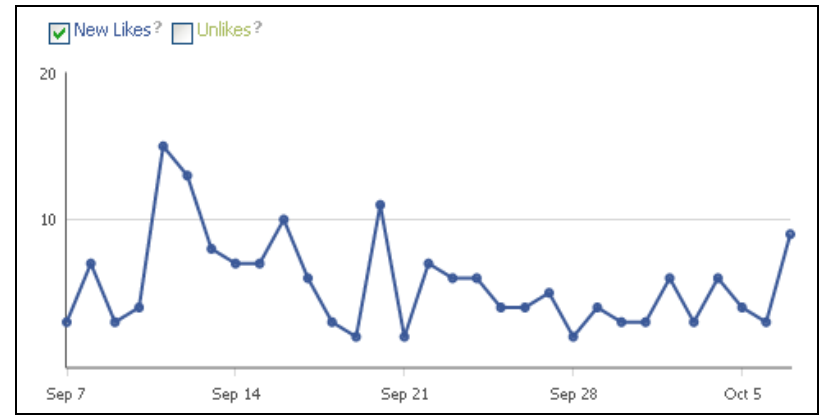

Fig. 5. Number of new "likes"

It should be appreciated that this form of marketing is only one part of the political communication that one political party is doing. Fulfilling the goal is not measurable with absolute numbers and did not prove that only this way of communication achieve the result of number of the votes in a particular area. This suggests that it is necessary to segment targets in different areas and to measure their achievement in other ways such as the number of visits from certain territorial and virtual space.

Political subjects have recently begun to actively use this virtual space given on Facebook pages which are very easy to manage. However, without human factor, without control by human hands, without creativity of the human brain and without distribution of good ideas in a creative and planned way through various types of media that are used on social networks (announcement, statuses, photos, videos) it is impossible to fulfill the goal.

\section{CONCLUSION}

All the above-mentioned shows that the trends of future development of project management are moving in the direction of increasing the number of virtual organizations and the formation of virtual teams, wider usage of the Internet, Extranet and Intranet, and an increasing usage of computer support that becomes a component of each project.

Virtual teams become teams of future, and they lead modern organizations to gain competitive advantages and to improve their operations. The Internet, Extranet and Intranet have become integral part of each organization, and it is almost impossible to find a company which operates without using one of these forms of computer nets. Software, as a project management computer support, gives the organizations which use it an enormous advantage on competitive market and it enables organizations to keep race against the time and, to facilitate and speed up work on projects.

It can be concluded that these trends of development of computer support and virtualization of project management has greatly influenced the market situation, which leads us to conclude that the future trends of future development will continue in that direction.

\section{REFERENCES}

[1] Bram, T. (2011): The Top 5 Project Scheduling Software Programs,

[2] Kerzner H., (2003), Project Management, A System Approach to Planning, Scheduling and Controlling, John Willey \& Sons.

[3] Kerzner H., (2004), Project Management Case Studies, John Willey \& Sons.

[4] Les Pang, (2001): Understanding Virtual Organizations http://www.isaca.org/Journal/Past-Issues/2001/Volume-

6/Pages/Understanding-Virtual-Organizations.aspx/ (Accessed on: 2012-05-22)

[5] Majstorović V., (2001), Upravljanje proizvodnjom i projektima, (Production and Project Management), DAAAM International Vienna i Sveučilište u Mostaru.

[6] Majstorović V., (2010), Projektni menadžment, Sveučilište u Mostaru

[7] McFarlane, S (2011): The differences between intranet, Internet and Extranet http://www.brighthub.com/computing/enterprisesecurity/articles/63387.aspx (Accessed on: 2012-06-10)

[8] Omazić M. A., Baljkas S., (2005), Projektni menadžment, Sinergija, Zagreb.

[9] Panian Ž. (2004): Izazovi elektroničkog poslovanja http://bib.irb.hr/ (Accessed on: 2012-05-14)

[10] PMI, (2004), A guide to the Project Management Body of Knowledge (PMBOK - Guide), PMI.

[11] Shtub A., Bard J. F., Globerson Sh., (1994), Project Management, Engineering, Technology and Implementation, Prentice Hall

[12] Thomas, E. (2009): Management and Leadership - Managing Your Virtual Team http://www.strategydriven.com/ (Accessed on 2012-05-20)

[13] http://www.hazelden.co.za/Pages/Services.php/ (Accessed on: 2012-06-14)

[14] http://www.pmi.org/ (Accessed on: 2012-07-07)

[15] http://www.projektura.org/ (Accessed on: 2012-07-12)

[16] http://indikator.ba/ekonomija/13004-facebook-u-bih-1202780korisnika/ (Accessed on: 2012-07-30)

[17] http://www.facebook.com (Acessed on: 2012-09-07) 